\title{
Managing the Anomalous Vertebral Artery in C1-C2 Stabilization for Congenital Atlantoaxial Instability
}

\author{
Roopesh Kumar Vadivel Rathakrishnan ${ }^{1} \quad$ Sunil Kapilavayi Raghavendra ${ }^{1}$ \\ ${ }^{1}$ Institute of Neurosciences, Sri Ramaswamy Memorial Institutes for \\ Medical Sciences, Chennai, Tamil Nadu, India \\ J Neurol Surg B 2021;82(suppl S1):S63-S64. \\ Address for correspondence Roopesh Kumar Vadivel Rathakrishnan, \\ MBBS, MS, MCh, Department of Neurosurgery, Apollo Proton Cancer \\ Centre, 100 feet road, Tharamani, Chennai-600041, Tamil Nadu, India \\ (e-mail: roops1975@gmail.com).
}

\begin{abstract}
Keywords

- anomalous vertebral artery

- atlantoaxial stabilization

- cranial assimilation

Objectives This study aimed to demonstrate the technique of handling the anomalous vertebral artery in congenital atlantoaxial instability. The vertebral artery course can be variable in congenital atlantoaxial instability, especially if there is assimilation of atlas. The surgical technique to stabilize the atlantoaxial joint should ensure the patency and safety of the vertebral artery and prevents devastating stroke. Computed tomography (CT) angiography of the vertebral artery is mandatory in planning the surgical strategies. The vertebral artery can be injured during dissection of soft tissues between atlas and axis and can be compromised during distraction and instrumentation. The vertebral artery needs to be mobilized based on the tortuosity in the course during instrumentation and prevents compression of the artery against bony structures or screw heads. The vertebral artery has to be identified earlier in the course of dissection and should protect it. It is also imperative to choose the surgical approach that can be performed under vision using operative microscope rather than adapting blind procedures like transarticular screw. Here, in our present case, we demonstrate the technique of mobilizing the vertebral artery which was coursing medially preventing the access for the instrumentation and perform stabilization of atlantoaxial joint using Goel-Harms technique, and prevent its compression after placement of screw by deroofing the bony ridges of axis (-Figs. 1 and 2). We also emphasize the various technical nuances during the stabilization with distraction of joint space of atlas and axis.

The link to the video can be found at: https://youtu.be/pgURpF_jACc.
\end{abstract}

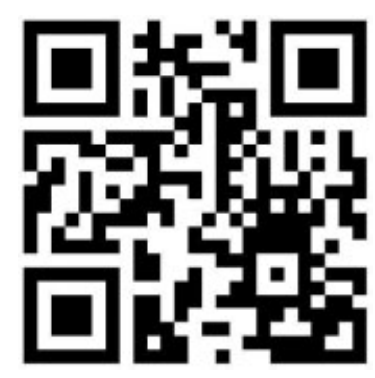

received

February 27, 2019 accepted after revision

March 8, 2020

published online

November 26, 2020

Conflict of Interest

None declared.

www.thieme.com/skullbasevideos

www.thieme.com/jnlsbvideos

DOI https://doi.org/ 10.1055/s-0040-1714404. ISSN 2193-6331. (c) 2020. The Author(s).

This is an open access article published by Thieme under the terms of the Creative Commons Attribution-NonDerivative-NonCommercial-License, permitting copying and reproduction so long as the original work is given appropriate credit. Contents may not be used for commercial purposes, or adapted, remixed, transformed or built upon. (https://creativecommons.org/ licenses/by-nc-nd/4.0/) Georg Thieme Verlag KG, Rüdigerstraße 14, 70469 Stuttgart, Germany 


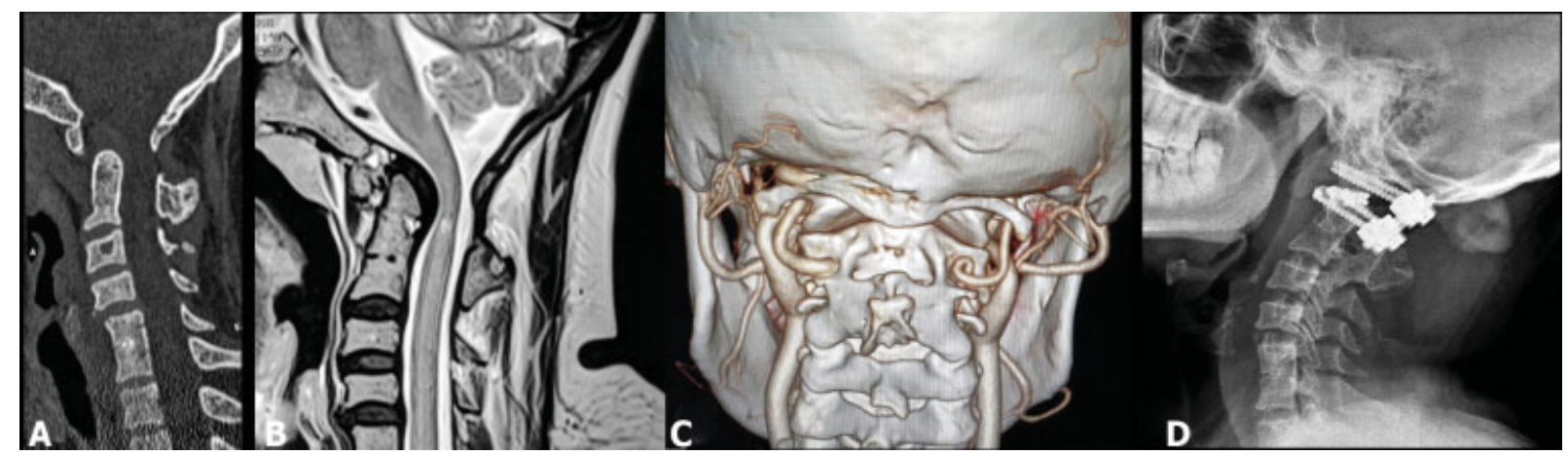

Fig. 1 (A) Sagittal CT scan - bone window shows Cranial Assimilation of Atlas. (B) T2 weighted sagittal image shows atlantoaxial dislocation with indentation of the cervicomedullary junction anteriorly and $\mathrm{T} 2$ hyperintense changes in the cord. (C) 3D CT angio shows anomalous position of the vertebral artery on the left side coursing more medially near the C2 pedicle. (D) Postoperative X-ray shows C1 lateral mass and C2 pedicle screws with spacers in the C1 C2 joint space.
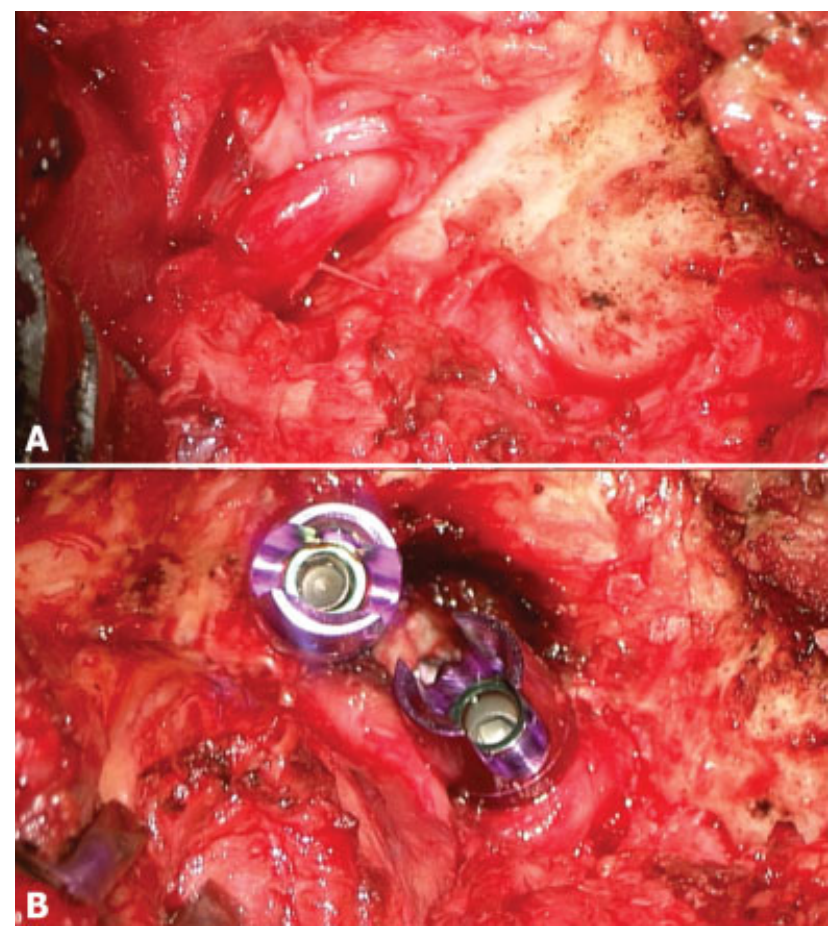

Fig. 2 (A) Intraoperative image shows the vertebral artery being more medially located on the C2 lamina; (B) Intraoperative image shows the position of the screws and the vertebral artery free from the position of the screws. 